\title{
Anterior Cruciate Ligament Reconstruction using Bone Patellar Tendon Bone autograft in ACL deficient Knee
}

\author{
Navin Kumar Karn' ${ }^{1}$, Ranjiv Kumar Jha ${ }^{2}$, Nishit Ranjan² \\ ${ }^{1}$ Nobel Medical College Teaching Hospital, Biratnagar, Nepal; Neuro Hospital Pvt. Ltd., Biratnagar \\ ${ }^{2}$ Nobel Medical College Teaching Hospital, Biratnagar, Nepal
}

Correspondence
Dr. Navin Kumar Karn
Associate Professor,
NMCTH,
Consultant Orthopedic
Surgeon \& HOD,
Department of Orthopaedics,
Neuro Hospital Pvt Ltd,
Biratnagar, Nepal.
Email:
navinkarn@yahoo.com

DOI:

http://dx.doi.org/10.3126/

jcmsn.v11i3.14057

\begin{abstract}
Background \& Objectives: Injury to Anter ior Cruciate Ligament (ACL) reconstruction has increased because of increased interest in sports. There are various grafts used for reconstruction of ACL, for example, Bone Patellar Tendon Bone, Hamstring etc. The study was conducted to evaluate the results of Bone Patellar Tendon Bone graft used for reconstruction of Anterior Cruciate Ligament. Materials \& Methods: 40 patients with chronic ACL deficient knee presenting to Neuro Hospital from July 2011 to June 2013 were included in the study. The patients with intraarticular fracture of knee, severe OA knee, local active or suspected infection and systemic disease that might influence the study results were excluded from the study. Bone patellar tendon bone graft was harvested from ipsilateral knee in all the cases. The patient was followed till 2 year with specified programme of rehabilitation. The pain was assessed using VAS and the function of the knee was assessed using Modified WOMAC knee index. Results: The long term satisfactory results in terms of functional stability, symptom relief and return to preinjury level of activity was seen in 32 cases(80\%). Two knees got infected out of which one required arthroscopic debridement. Mean visual analogue scale was 8 and modified WOMAC knee score was 3 at 2 year follow up. Conclusion: Bone patellar tendon bone graft is useful in high demand patients and cost effective option with high patient satisfaction rate for reconstruction of ACL.

Key words: ACL reconstruction, arthroscopic treatment, bone patellar tendon bone
\end{abstract}

Citation: Karn NK, Jha RK, Ranjan N. Anterior Cruciate Ligament Reconstruction using Bone Patellar Tendon Bone autograft in ACL deficient Knee. JCMS Nepal. 2015;11(3):12-15.

\begin{tabular}{|c|c|}
\hline $\begin{array}{l}\text { INTRODUCTION } \\
\text { Injury to Anterior Cruciate Ligament (ACL) } \\
\text { reconstruction has increased because of increased } \\
\text { interest in sports. Rupture of ACL may lead to } \\
\text { instability, pain, swelling, mechanical dysfunction } \\
\text { and an increased risk of meniscal injury and } \\
\text { degenerative changes. }{ }^{-5} \text {. } \\
\text { Non operative treatment may lead to suboptimal } \\
\text { knee function and to joint detoriation. }{ }^{4,6,7} \text { For this } \\
\text { reason many procedures have been developed to } \\
\text { restore stability and allow patient to have more } \\
\text { active life. The reconstruction of ACL with central } \\
\text { third of patellar tendon with proximal and distal } \\
\text { bone blocks has been shown to produce dependable } \\
\text { results. }{ }^{2,8} \text { The fixation of these grafts is most } \\
\text { commonly performed with metal or bioabsorbable } \\
\text { interference screw. This procedure is well }\end{array}$ & $\begin{array}{l}\text { documented with good results. }{ }^{2,9,10} \text { The } \\
\text { development of new fixation methods and } \\
\text { endoscopic techniques has decreased the morbidity } \\
\text { of ACL reconstruction without compromising the } \\
\text { results. }{ }^{11} \text { However graft site problems and anterior } \\
{\text { knee pain continue to be concern }{ }^{12} \text { Less donar site }} \text { morbidity has been reported using the hamstring } \\
\text { tendon }{ }^{13} \text { Both surgical procedures result in knees } \\
\text { with good stability. }{ }^{13,14,15} \text { The study was conducted } \\
\text { to evaluate the results of Bone Patellar Tendon } \\
\text { Bone graft used for reconstruction of Anterior } \\
\text { Cruciate Ligament. } \\
\text { MATERIALS AND METHODS } \\
40 \text { patients between } 20 \text { and } 50 \text { years with ACL } \\
\text { deficient knee presenting to Neuro Hospital from } \\
\text { July } 2011 \text { to June } 2013 \text { were included in the study. }\end{array}$ \\
\hline
\end{tabular}


The patients received written and oral information about the study and signed a written consent. The patients with intraarticular fracture of knee, severe OA knee, local active or suspected infection and systemic disease that might influence the study results were excluded from the study. The knee was examined clinically than arthroscopically under spinal anesthesia. The concomitant pathology of the knee was treated. The graft was harvested from the middle third of the ipsilateral ligamentum patellae. The surgical technique with the bone patellar tendon bone graft was a standard endoscopic procedure as described. ${ }^{10}$ If necessary, notchplasty was done. A tibial guide was used that is designed to place the guide pin $4-5 \mathrm{~mm}$ posterior and parallel to the slope of intercondylar roof with the knee in full extension. The femoral aimer was inserted through the tibial tunnel and hooked in the over the roof position at 10 o'clock for right knee and 2 o'clock for left knee. The femoral bone block was fixed from the inside with a cannulated interference screw. The knee was cycled several times, and the grafts were tensioned. The bone block in the tibial tunnel was fixed with an interference screw with knee in full extension. The wound was closed in layers. The patient was followed at 2 weeks, 6 weeks, 3 months, 6 months, 1 year and 2 year with specified programme of rehabilitation. At every follow up we assessed for range of motion, patellofemoral crepitation, effusion, Lachman test, pivot shift test and clinical examinations were performed. The pain was assessed using VAS and the function of the knee was assessed using Modified WOMAC knee index.

\section{RESULT}

Total number of patients was 40 and mean follow up was for 2 years. The gender distribution of patient is given in Table 1 and the different modes of injury in Table 2. Fall from height was commonest mode of injury. The medial meniscus was torn in twenty four knees $(60 \%)$ and lateral meniscus in 4 knees $(10 \%)$. The arthroscopic view of rupture of ACL is shown in Fig 1 and associated

Table 1. Gender based distribution of patients

\begin{tabular}{lll}
\hline Gender & No of cases & Percentage \\
Male & 26 & 65 \\
Female & 14 & 35 \\
\hline
\end{tabular}

Table 2. Different modes of injury

$\begin{array}{lll}\text { Mode of injury } & \text { No of cases } & \text { Percentage } \\ \text { Sports related } & 6 & 15 \\ \text { Fall } & 20 & 50 \\ \text { RTA } & 14 & 35 \\ \text { Total } & 40 & 100\end{array}$

Table 3. Subjective assessment

\begin{tabular}{|cll|}
\hline & $\begin{array}{l}\text { Mean Modified } \\
\text { WOMAC Knee } \\
\text { Score }^{+}\end{array}$ & $\begin{array}{l}\text { Mean visual } \\
\text { analogue scale }_{\text {score }^{++}}\end{array}$ \\
\hline Preoperative & 24 & 5 \\
3 months & 16 & 8 \\
6 months & 10 & 8 \\
1 year & 3 & 8 \\
2 years & 3 & 8 \\
\hline
\end{tabular}

tear of medial meniscus in Fig 2. We performed partial meniscectomy in all the cases of torn meniscus because repair was not possible in either of case. Postoperative radiograph is shown in that shows bone tendon bone graft fixed with interferential screw on femoral side and interferential screw and staple on tibial side Fig 3. The bone tendon bone graft harvested from same knee and is shown in Fig 4. The mean visual analog score and mean modified WOMAC knee index showed a progressive and substantial improvement as compared to preoperative condition and is shown in Table 3. Extension deficit was assessed with the patient lying in the prone position and was measured as the differencae in the heel height of the involved limb in comparison with that of the contralateral, uninjured limb in full passive extension. At the six month follow-up evaluation only three knee showed 3-5 degree extension loss. At the two year follow up examination there was progressive recovery of knee extension and only one knee had a persistent 3 degree extension loss. At the two year follow up evaluation moderate but asymptomatic patellofemoral crepitation was recorded in eight knees $(20 \%)$ and anterior knee pain with kneeling discomfort in 10 knees $(25 \%)$

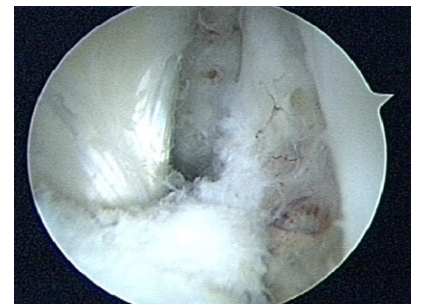

Fig 1. Torn Anterior Cruciate Ligament

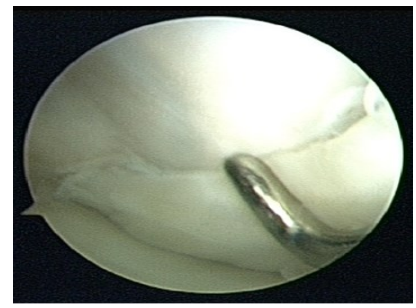

Fig 2. Tear of medial meniscus 


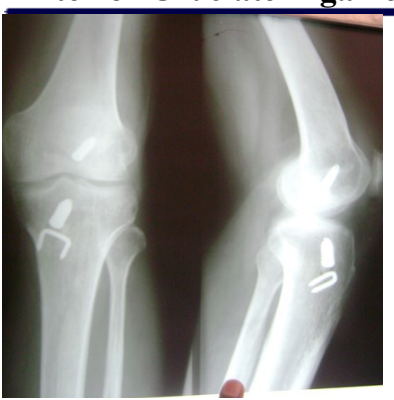

Fig 3. Post operative radiograph

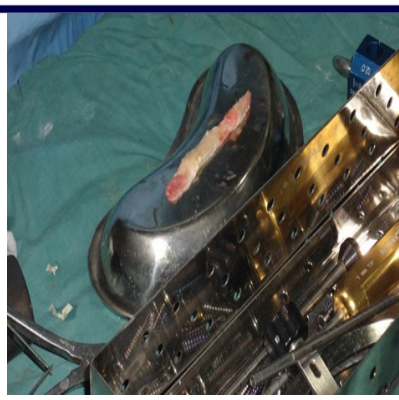

Fig 4. Bone patellar tendon bone graft

We noticed mild effusion in 4 knees $(10 \%)$ that resolved by 6 weeks in all the cases. Anterior tibial translation as demonstrated by the Lachman test was restored to within $5 \mathrm{~mm}(+1)$ and with a firm end point in all patients for all follow up visits for upto two years after surgery. At the two year follow up examination a pivot shift glide was recorded in 10 knees $(25 \%)$. No patient reported symptoms of giving way or showed a pivot shift clunk $(+2) .2$ Knees got infected out of which one was superficial infection that was treated with local wound care and oral antibiotic. One knee got deep infection that required arthroscpic debridement. 6 patients went back to his sports activity. 20 patients doing heavy work as manual labour. 32 patients $(80 \%)$ has shown high patient satisfaction rate. We used titanium screw in all the cases to reduce the cost and average cost involved per case was Rs 18000/(US \$ 180).

\section{DISCUSSION}

The bone patellar tendon bone autograft has traditionally been considered gold standard in ACL reconstruction. ${ }^{16}$ No graft type has consistently been proven to be superior. In a recent meta analysis comparing patellar tendon and hamstring graft for ACL reconstruction, no significant difference in stability was demonstrated but patellar tendon graft were more likely to result in reconstruction with normal Lachman, normal pivotshift and KT-1000 manual maximum side-side difference of less than $3 \mathrm{~mm} .{ }^{17}$ Salmon LJ et a ${ }^{18}$ has reported half of patients developed loss of extension but we found only three knees out of 40 has extension loss at 6 months and one had persistent loss of extension at two years of 3 degree. Salmon $\mathrm{LJ}$ et al ${ }^{18}$ also noticed that patients who has undergone meniscectomy at the time of reconstruction had increased clinical ligament laxity

over time and greater odds of graft rupture but we did not find such correlation in our study possibly because of short duration of follow up. Salmon LJ et $\mathrm{al}^{18}$ has reported degenerative changes of knee in radiograph in $79 \%$ of patients and Lebel $\mathrm{B}^{19}$ et al has reported knee osteoarthritis in $17.8 \%$ but we have observed osteoarthritis knee only in 5\% cases could be because of short follow up of 2 years. Mohtadi $\mathrm{N}^{20}$ has shown more traumatic rupture in hamstring group as compared to patellar tendon group in his randomized controlled trial. We have not encounter rupture till 2 yrs follow up. We used transtibial drilling for femoral tunnel in all the cases that could be one of the reason for laxity in our earlier follow up of patients. The study done by Alentorn Geli $E^{21}$ has shown use of anteromedial portal elicited greater knee stability and range of motion values and earlier return to run as compared to the transtibial technique. We used metallic screw for fixation and cost is reduced as compared to biodegradable screw.

\section{CONCLUSION}

We conclude that Bone patellar tendon bone graft is useful in high demand patients and cost effective option with high patient satisfaction rate for reconstruction of ACL. We recommend a randomized controlled trial comparing bone patellar tendon bone and hamstring graft.

\section{REFERENCES}

1. Arnold JA, Coker TP, Heaton LM, Park JP, Harris WD Natural history of anterior cruciate tears Am J Sports Med. 1979;7:305-13.DOI: $\quad 10.1177 / 036354657900700601$; PMID:507265.

2. Drogset JO, Grontvedt $\mathrm{T}$ Anterior cruciate ligament reconstruction with and without a ligament augmentation device : results at 8-Year follow-up.Am J Sports Med. 2002;30:851-6. PMid:12435652

3. Feagin JA Jr, Curl WW Isolated tear of the anterior cruciate ligament: 5-year follow up study Am J Sports Med 1976;4:95-100. DOI: 10.1177/036354657600400301; PMID:984289.

4. Hawkins RJ, Misamore GW, Merritt TR Follow up of the acute nonoperated isolated anterior cruciate ligament tear Am J Sports Med. 1986; 14:205-10. DOI: 10.1177/036354658601400305; PMID:3752360.

5. Jacobsen K Osteoarthritis following insufficiency of the cruciate ligaments in man. A clinical study. Acta Orthop Scand. 1977:48:520-26. 10.3109/17453677708989742; PMID:596150.

6. Bray RC, Dandy DJ Meniscal lesion and chronic anterior cruciate ligament deficiency. Meniscal tear occurring before and after reconstruction J Bone Joint Surg. 1989 (Br);71:128-30. 
7. Buss DD, Min R, Skyhar M, Galinat B, Warren RF, Wickiewicz TL Nonoperative treatment of acute anterior cruciate ligament injuries in a selected group of patients. Am J Sports Med. 1995;23:160-5.

DOI: $10.1177 / 036354659502300206$.

8. Drogset JO, Grontvedt T, Tegnander A Endoscopic reconstruction of the anterior cruciate ligament using bone patellar tendon bone grafts fixed with bioabsorbable or metal interference screws: a prospective randomized study of the clinical outcome. Am J Sports Med. 2005;33:1160-5. DOI: 10.1177/0363546504272264; PMID:16000666.

9. Barber FA. Bioscrew fixation of patellar tendon autografts.Biomaterials. 2000;21:2623-9. DOI: 10.1016/ S0142-9612(00)00130-7.

10. Droget JO, Grontvedt T, Robak OR, Molster A, Viset AT, Egebretsen L A sixteen year follow up of three operative technique for the treatment of acute ruptures of anterior cruciate ligament. J Bone Joint Surg Am. 2006;88:944-52. DOI: 10.2106/JBJS.D.02876. PMID:16651567.

11. Fauno $P$, Kaalund $S$ Tunnel widening after hamstring anterior cruciate ligament reconstruction is influenced by the type of graft fixation used: a prospective randomized study. Arthroscoy. 2005;21:1337-41. DOI: 10.1016/ j.arthro.2005.08.023 PMID:16325084.

12. Kartus J, Stener S, Lindahl S, Engstrom B, Karlsson J Factors affecting donar site morbidity after anterior cruciate ligament reconstruction using bone patellar tendon bone autografts. Knee Surg Sports Traumatol Arthrosc. 1997;5:222-8. DOI: $\quad 10.1007 / \mathrm{s} 001670050054$; PMID:9430571.

13. Aune AK, Holm I, Risberg MA, Jensen HK, Steen H Four strand hamstring tendon autograft compared with patellar tendon bone autograft for anterior cruciate ligament reconstruction. A randomized study with two-year follow up. Am J Sports Med 2001;29:722-8. PMID:11734484.

14. Aglietti P Patellar tendon versus doubled semitendinosus and gracilis tendons for anterior cruciate ligament reconstruction Am J Sports Med. 1994;22:211-7. DOI: 10.1177/036354659402200210. PMID:8198189.

15. Harilainen A, Linko E, Sandelin J Randomized prospective study of ACL reconstruction with interference screw with patellar tendon autografts versus femoral metal plate suspension and tibial post fixation in hamstring tendon autografts: 5-year clinical and radiological follow-up results. Knee Surg Sports Traumatol Arthrosc. 2006;14:517 -28. DOI: 10.1007/s00167-006-0059-0; PMID:16552549.

16. Abate JA, Fadale PD, Hulstyn MJ, Walsh WR. Initial fixation strength of polylactic acid interference screw in anterior cruciate ligament reconstruction Arthroscopy. 1998;14:278-84. DOI: 10.1016/S0749-8063(98)70143-4.

17. Goldblatt JP, Fitzsimmons SE, Balk E, Richmond JC. Reconstruction of the Anterior Cruciate Ligament: Metaanalysis of Patellar Tendon versus Hamstring Tendon Autograft. Arthroscopy. 2005;21:791-803. DOI: 10.1016/ j.arthro.2005.04.107; PMID:16012491.

18. Salmon LJ, Russell VJ, Refshauge K, Kader D, Connolly C, Linklater J, Pinczewski LA. Long term outcome of endoscopic anterior cruciate ligament reconstruction with patellar tendon autograft: minimum 13-year review. Am J Sports Med. 2006 May;34(5):721-32. DOI: 10.1177/0363546505282626. PMID:16399931.

19. Lebel B, Hulet C, Galaud B, Burdin G, Locker B, Vielpeau $\mathrm{C}$ Arthroscopic reconstruction of the anterior cruciate ligament using bone patellar tendon bone autograft: a minimum 10 year follow up. Am J Sports Med. 2008 Jul;36
DOI:

PMID:18354147.

20. Mohtadi N, Chan D, Barber R, Paolucci EO. Reruptures, Reinjuries, and Revisions at a Minimum 2-Year Follow-up: A Randomized Clinical Trial Comparing 3Graft Types for ACL Reconstruction.Clin J SPORT Med. 2015 Jun 29 [Epub ahead of print]. DOI: 10.1097/ JSM.0000000000000165

21. Alentorn-Geli E, Lajara F, Samitier G, Cugat R The transtibial versus the anteromedial portal technique in the arthroscopic bone-patellar tendon-bone anterior cruciate ligament reconstruction Knee Surg Sports Traumatol Arthrosc. 2010 Aug;18(8):1013-37. DOI: 10.1007/s00167009-0964-0; PMID:19902178. 